\title{
Oral Diseases Panorama in Dermatology: An Observational Study
}

\author{
Mohd Rizwan khan \\ Consultant Dermatologist and Leprologist, Shahjahanpur, Uttar Pradesh \\ Corresponding author: Mohd Rizwan khan; ahmedaleidan@gmail.com
}

Received 30 August 2020;

Accepted 28 September 2020;

Published 01 October 2020

\begin{abstract}
Background: The oral cavity is a mirror of the body, entry point to food, antigens, and microorganisms. Oral cavity with mastication and speech, also have a role play in immunological defense. The Oral mucous membrane is in link with skin, oropharynx, and nasopharynx. The oral cavity and anterior two-thirds of the tongue are formed by the ectoderm and that is why from a dermatologist's viewpoint, an oral opening is especially imperative and involved in a range of systemic and skin disease, also affect teeth and gums. The body's natural protection is in good quality oral care. Oral problems when associated with skin conditions require oral care as it affects the quality of life and enable dermatologist and dentist in the identification and diagnosing of systemic disease. Oral illness can bring into being from infection, inflammation or neoplastic, immunological, benign, or malignant. Results: The oral cavity is a mirror to a variety of systemic and cutaneous diseases. Interpretation of the symptom and signs of systemic diseases help early diagnosis. However, while not correct oral hygiene, microorganisms will reach levels that may result in oral infections and decay. The health status of our oral cavity can give us a strong signal of the health of our bodies. It proceeds as a premature warning system. That's why the oral cavity should be examined in one piece from the buccal mucosa to the oropharynx. $\underline{C o n c l u s i o n}$ : The mouth is a straightforwardly available window of the body. In contemplation with development, composition, and utility oral cavity is only one of its kind. It is a two-way road as systemic skin disease has oral manifestation. Interpretation of the symptom and signs help in identification and early diagnosis of systemic diseases. Oral illness can bring into being from infection, inflammation or neoplastic, immunological, benign, or malignant. That's why the oral cavity should be examined in one piece from buccal mucosa, lips, tongue, gum, teeth, palate to the oropharynx. Knowledge of systemic diseases is vital in day to day clinical practice, often oral manifestation is the most significant or first sign of systemic illness. So dermatologists and dental surgeons are conscious of oral complaints and their association with systemic disease.
\end{abstract}

Keywords: Leukoedema, White sponge nevus, Pachyonychia congenital, Dyskeratosis congenital, Oral Hairy Leukoplakia, Linea alba, Keratosis, Leukoplakia, Actinic cheilitis, Submucosal Fibrosis, Aphthous ulcer, Behcet's syndrome, Herpes simplex, Coxsackie virus, Acute necrotizing ulcerative gingivitis, Oral Lichen Planus, Pemphigus, Mucous Membrane Pemphigoid, Paraneoplastic Pemphigus, Reiter's syndrome, Linear IgA Disease, Dermatitis Herpetiformis, Actinic cheilitis

\section{Introduction}

Oral illness can bring into being from infection, inflammation or neoplastic, immunological, benign, or malignant. That's why the oral cavity should be examined in one piece from buccal mucosa, lips, tongue, gum, teeth, palate to the oropharynx.

Tooth mobility - also called as a loose tooth. When a tooth is displaced horizontally or vertically from its boundaries ${ }^{[1]}$. Tooth loss implies the loss of several structures like bone, nerves, and muscles. If there is supporting tissue damage it will lead to necrosis of alveolar bone and cause a decrease in the number of teeth. The patient feels difficulty in chewing, poor speech, pain and poor appearance, which decrease quality of life ${ }^{[2]}$.
Dental sinuses and abscess - it may form at the periapical and discharges into the oral cavity. An infection like actinomycosis can affect the cheeks and mandible.

Discoloration of teeth - can be seen in lots of causes-1. In some genetic development defects, teeth show discolorations like imperfect and appear brown or grey. 2. In systemic condition teeth produce different color like neonatal jaundice appear green, in erythropoietic porphyria appear yellow (Fig. 1)., in fluorosis enamel appear mottled, tetracycline intake during pregnancy produces yellow to brown. Causes are listed in Table-1.

Table 1: Causes of teeth discoloration.

\begin{tabular}{|l|l|}
\hline Intrinsic causes & $\begin{array}{l}\text { Caries, Aging, Porphyria, Fluorosis, } \\
\text { Drugs, Poor hygiene, Trauma }\end{array}$ \\
\hline Extrinsic causes & $\begin{array}{l}\text { Chewing paan, Bacterial infection, Food } \\
\text { like tea, wine, Smoking, Mouth rinses. }\end{array}$ \\
\hline
\end{tabular}




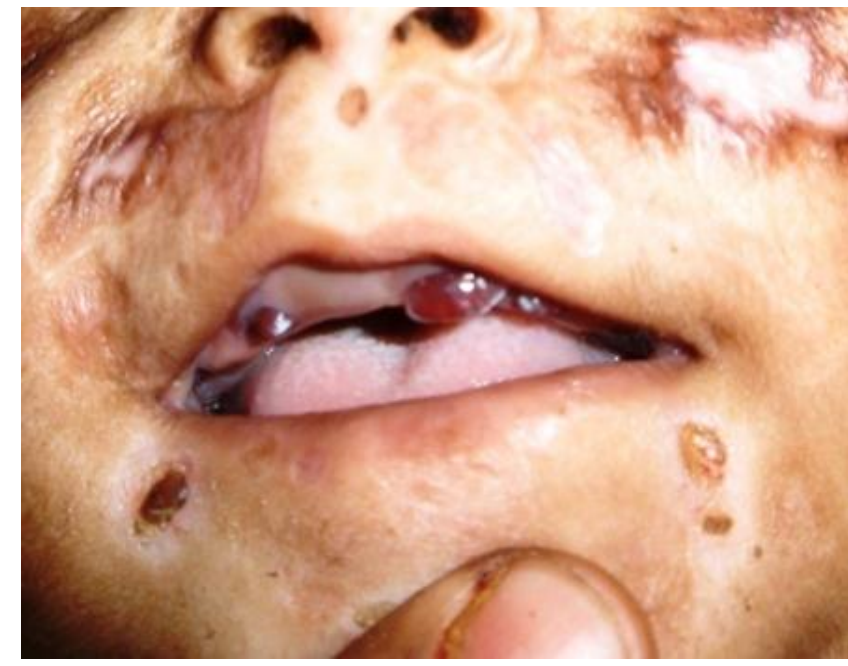

Fig 1: Porphyria: Erythrodontia, loss of teeth, healed vesiculobullous lesion with scaring.

Loss of teeth - disorder like down syndrome, papillon-leferve syndrome, and scurvy cause early exfoliation of teeth, local causes like trauma, dysplasia, periodontis, osteomyelitis cause mobility, and loss. Causes are listed in Table- 2

Table 2: Pathological causes of loose teeth

\begin{tabular}{|l|l|}
\hline Local causes & $\begin{array}{l}\text { Caries, Neoplasm, Trauma, Periodontal } \\
\text { disease }\end{array}$ \\
\hline Systemic causes & $\begin{array}{l}\text { Diabetes, Down syndrome, Leukemia, } \\
\text { Osteomyelitis }\end{array}$ \\
\hline
\end{tabular}

Disorders affecting Periodontium - Periodontium consist of the gingival, periodontal ligament, alveolar bone, and collagenous covering adjoining the teeth.

- Gingival Colour: Color varies rely upon vascular provide, organic process, melanin, and thickness of gum. Different causes that turn out pigmentation are periodontal disease, erythroplasia, pathology, hemangioma, Crohn's, and Wegener's sickness.

- Gingival Ulcer: it occurs when annoying materials that come in contact with periodontal tissues for a long time. Other causes are viral infections, aphthous ulcer, drugs, hematological diseases, tuberculosis, syphilis

- Gingival Beeding: Poor dental hygiene leads to food and bacteria cover the tooth surface, infection, and periodontal inflammation cause destruction, erosion, and ulceration. There is bleeding from the gentle manipulation of the tissue or probing. Causes are listed in Table-3

Table 3: Pathological causes of gingival bleeding

\begin{tabular}{|l|l|}
\hline Local causes & $\begin{array}{l}\text { Acute necrotizing, Ulcerative gingivitis, } \\
\text { Periodontitis }\end{array}$ \\
\hline $\begin{array}{l}\text { Systemic } \\
\text { causes }\end{array}$ & $\begin{array}{l}\text { Drugs, Hemophilia, Leukemia, Polycythemia } \\
\text { vera, Scurvy, Thrombocytopenia }\end{array}$ \\
\hline
\end{tabular}

a. Gingival Swellings - also known as gingival hyperplasia or hypertrophy it is an irregular expansion of gingival tissues. Causes are listed in Table 4

Table 4: Pathological causes of gingival swellings

\begin{tabular}{|l|l|}
\hline $\begin{array}{l}\text { Metabolic } \\
\text { disorder }\end{array}$ & $\begin{array}{l}\text { Amyloidosis, Lipoid proteinosis, } \\
\text { Mucopolysaccharidoses }\end{array}$ \\
\hline Drugs & Phenytoin, Cyclosporine, Diltiazem \\
\hline
\end{tabular}

\begin{tabular}{|l|l|}
\hline $\begin{array}{l}\text { Plaque } \\
\text { induced }\end{array}$ & Hyperplastic gingivitis, Chronic gingivitis \\
\hline Hematological & Hypoplasmino-genemia, Leukemia \\
\hline Others & $\begin{array}{l}\text { Pregnancy, Sarcoidosis, Scurvy, Crohn's } \\
\text { disease, Wegener's }\end{array}$ \\
\hline
\end{tabular}

b. Neumann's tumor - or Congenital Epulis. It's a rare, benign, well sessile nodule. There's a proliferation of cells mainly on the gum ridge of maxilla5. Interfere with respiration and feeding.

c. Hereditary Gingival Fibromatosis - is an associate degree uncommon style of gingival overgrowth ${ }^{[3]}$. Its chromosome dominant, anomalies at a pair of or five chromosomes. There's benign, slowly progressive, and enlargement that may cowl teeth in a very vary of extent and may cause aesthetic disfigurement ${ }^{[4]}$. could also be related to hypertrichosis, backwardness, and abnormality

d. Pregnancy Gingivitis - usually develops in the second month and peaks around eight months. Increased levels of progesterone make easy bacterial growth. Gums grow to be edematous, reddish and have a propensity to bleed. Oral hygiene should be enhanced.

e. Drug-induced gingival swelling - pathogenesis is not well understood. More than 20 drugs are associated ${ }^{[6]}$ and tear down quality of life. Risk factors consist of gingivitis, plaque, dose, duration, and periodontal pocket deepness. Side effects of drugs cause swelling, bleeding, intricacy in chewing, and talking. Some hypotheses suggest the role of factors as a. Fibroblast ${ }^{[7]}$, b. inflammatory cycytokines 8 and c. Matrix metalloproteinase synthesis ${ }^{[9,10]}$. Incidence $\%$ in Table 5.

Table 5: Drugs causing Gingival swelling

\begin{tabular}{|l|c|}
\hline Drugs & Incidence \% \\
\hline Cyclosporine & 39.4 \\
Mycophenolate mofetil & 13.1 \\
Phenytoin, & 65.4 \\
Amlodipine & 94.8, \\
Nifedipine & 57.9 \\
Carbamazepine & 15.1 \\
\hline
\end{tabular}

f. Chronic Periodontitis - could be a common malady consisting of chronic inflammation of odontology tissues ${ }^{[11]}$. It happens in the main because of the buildup of exuberant amounts of plaque. It begins in adolescence and become clinically significant in the mid-30s. The patient complains of redness, bleeding gums usually marginally while using dental floss, brushing or probing, gum swelling, halitosis, and gingival recession resulting in deep pockets ${ }^{[12]}$. Effective treatment is scaling and mechanically debride and disrupts the biofilm by SRProot planning ${ }^{[13]}$.

g. Desquamative Gingivitis - expresses as red painful, erosion of gingiva. It is usually seen in middle-aged females. There is desquamation extend beyond the margin of gingival and sometimes the alveolar mucosa ${ }^{[14]}$. Have an effect on females aged between $30-40$ years. Predominantly affects the buccal and labial gingiva. Treatment is to increase oral hygiene, treating the underlying condition, and topical corticosteroids.

h. Allergic Gingivostomatitis - it is a hypersensitive reaction to candy, toothpaste, and change of state gum place during a vulnerable atopic. There's a formation of the sore mouth that is commonly intense by spicy food, 
the tissue is erythroderma and diffusely enlarged. Chronic exposure might end in a lichenoid lesion. Treatment is to avoid allergens, betamethasone rinses, topical corticosteroid, and fusidic acid.

i. Fibroepithelial Polyp - it's sometimes seen in adults. It's delineating by red, pink or white like enlargement, ofttimes on the animal tissue, tongue, and lip however are often all over on the oral mucous membrane. It's sometimes single, small, and usually painless and caused by trauma consequent accidental biting. Treatment is excision.

\section{Disorder of the oral mucosa}

Pigmented Lesions - pigmentation of the oral cavity occur due to various causes, besides also from foreign bodies, heavy metal, deposition of exogenous material, or drug-induced. Pigmentation varies in intensity, extent, depth, and amount of melanin production. Pigmentation can appear at any site of the oral cavity. Various causes are listed in Table 6

Table 6: Causes of Oral pigmentation

\begin{tabular}{|l|l|}
\hline Benign/ malignant & $\begin{array}{l}\text { Melanocytic nevi, Melanoacanthoma, } \\
\text { Melanoma }\end{array}$ \\
\hline Physiological & Pregnancy, Racial, Ephelids \\
\hline Chemical induced & Smoking, Heavy metal, Drugs, Amalgam \\
\hline Pathological & $\begin{array}{l}\text { Peutz-jeghers syndrome, Lichen planus } \\
\text { nigricans, Endocrine disease, HIV } \\
\text { infection }\end{array}$ \\
\hline
\end{tabular}

a) Physiological Pigmentation - is frequent and outcome from enhance in the creation of melanin pigment by the melanocytes ${ }^{[15]}$. Dark-skinned human beings are frequently affected. Pigmentation ranges from light brown to black, increases with age, and concentration can be prejudiced by hormones, smoking, and medication ${ }^{[16]}$. Due to increasing levels of estrogen and progesterone in pregnancy stimulate melanocytes and results in hyperpigmentation. Due to sun exposure, small brown macules appear on lips and perioral skin called ephelides.

b) Chemical induced Pigmentation - this is often because of the stimulation of animal pigment production induced by vasoconstrictive called 'smoker melanosis'. Improves with stop smoking. Some medications will cause pigmentation of the oral mucous membrane as an instance medicine like estrogen, ketoconazole, busulfan, antimalarials, etc. Significant metal also can cause pigmentation while not stimulating animal pigment as instance arsenic, lead, bismuth, mercury, and atomic number 78. Accidental implantation of the alloy will cause tattoo, these macules vary in form and size.

c) Pathological causes - in Addison's disease, Cushing's syndrome and hypothyroidism black to brown pigmentation of gums and mucosa may present. There is an increase in melanin in Peutz-jeghers syndrome and present with freckles at lips and oral mucosa. In Lichen Planus Nigricans and pemphigus there is brownish pigmentation in superficial layers due to the postinflammatory process and melanin ingested from macrophages. Oral melanotic macules have been found in HIV infected patients.

d) Benign and malignant lesions - Melanocytic Nevi is rare, well-circumscribed, they can be brown, grey, or black, and the intramucosal variant is frequent and commonly situated on the buccal mucosa and hard palate ${ }^{[17]}$. Oral melanoacanthoma (Fig. 2) is rare ${ }^{[18]}$, benign, and has mixed cell proliferation; pathogenesis is uncertain but suggestive of reactive nature. It present as an asymptomatic, flat, solitary, pigmented lesion commonly on traumatic sites of the buccal mucosa. Oral melanoma only $1-2 \%$ are seen, present as brown macule that may progress in size ${ }^{[19]}$. Frequent sites are hard palate and gums also seen on lips and buccal mucosa.

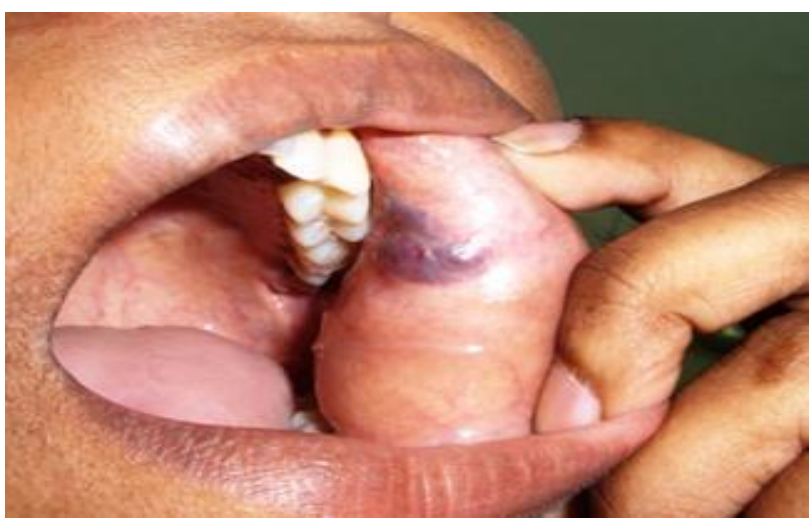

Fig-2: Melanocytic Nevi: Well-circumscribed, grey or black, intramucosal at the left cheek.

White lesions of the Oral Cavity- when the distance between the epidermis and blood vessels is increased it will produce white lesions, this occurs due to hyperkeratosis, acanthosis, and edema. Causes are listed in Table 7.

Table 7: causes of white lesions of the oral cavity

\begin{tabular}{|l|l|}
\hline Developmental & $\begin{array}{l}\text { Leukoedema, White sponge nevus, } \\
\text { Pachyonychia congenital, Dyskeratosis } \\
\text { congenital, Hereditary benign intraepithelial } \\
\text { dyskeratosis }\end{array}$ \\
\hline Infections & Oral hairy leukoplakia \\
\hline Inflammatory & $\begin{array}{l}\text { Linea alba, Frictional keratosis, Chemical } \\
\text { keratosis, Thermal keratosis }\end{array}$ \\
\hline Neoplastic & $\begin{array}{l}\text { Leukoplakia, Actinic cheilitis, Submucosal } \\
\text { fibrosis }\end{array}$ \\
\hline
\end{tabular}

a) Leukoedema - seen in $90 \%$ rather than black adults, benign and etiology is unknown. gift as bilateral, chalky, gray-white, disperse, well normally on the buccal mucous membrane, and the classical feature is on stretching there's vanishing of the lesion. Augment with tobacco use.

b) White sponge nevus - its chromosome dominant, mutation of keratin4, or thirteen genes ends up in defective membrane keratinisation ${ }^{[20]}$. Presents from birth or developed through childhood, as, thick, symmetrical bilaterally, spongy, velvety, white plaques, positioned on the lip, ventral surface of the tongue, and floor of the mouth.

c) Pachyonychia congenital - it is AD chromosome disorder, describes by oral leukoplakic lesion ${ }^{[21]}$ on the tongue, buccal mucous membrane or animal tissue, angular redness, nail dystrophy, cyst multiplex, subungual and palmoplantar hyperkeratosis ${ }^{[22]}$.

d) Dyskeratosis congenital - it's a rare congenital disease, Dyskeratosis is that the irreversible degeneration of skin tissue seen in newborn ${ }^{[23]}$. They start with bullae formation followed by erosion and at last leukoplakic 
plaques. Oral leukoplakia lesions are visible in eightieth. The oral lesion is premalignant and should convert to epithelial cell cancer over 10-30 years.

e) Hereditary benign intraepithelial dyskeratosis - it's rare chromosome dominant, there's a duplication of body $4 q 35$, involving the mucosa and oral mucous membrane, oral lesions gift as well, spongy white plaques at the buccal and labial mucous membrane, gingiva, lateral tongue, and palate. It's self-limiting and benign nature. In the eye, it seems as jellylike plaques on the bulbar conjunctiva $^{[24]}$.

f) Oral Hairy Leukoplakia - it happens in HIV infection and disorder people by sculptor Barr virus ${ }^{[25]}$. It presents as well, vertically furrowed, or bushy like white lesion on a facet of the tongue (Fig-3). This lesion cannot be wiped away ${ }^{[26]}$. Benign and well thus no treatment required. Medicine and podophyllin are shown to be effective.

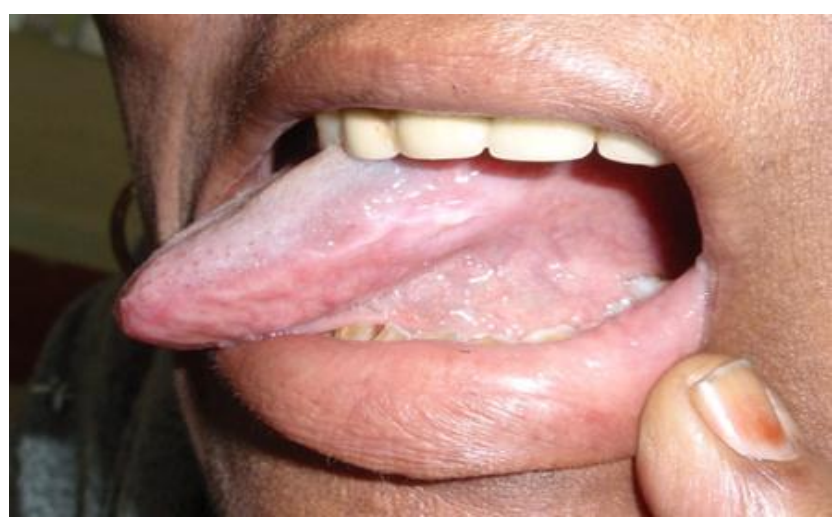

Fig-3: Oral hairy leukoplakia: White corrugated plaque on the lateral aspect of the tongue.

g) Linea alba - is specific to one kind of the white patch within the oral tissue layer, usually, this skin disorder will come into view as a skinny reference transversally the length of the cheek known as as a white line or linea alba opposite wherever the teeth meet. It will furthermore set out as a definite white patch anyplace within the mouth preponderantly on cheek or gums.

h) Keratosis - is caused by regular friction of the mouth, largely from teeth or dentures, and gives the white area. The body responds to the irritation and produces additional cells. If the premise of irritation is removed then the white patch ought to turn. If skin disorder seems with exposure to heat or excess hot food intake, then coined as thermal skin disorder the same method if keratosis seems to exposure to chemical substances known as chemical keratosis.

i) Leukoplakia - it's a premalignant lesion and a clinical term and has no specific histological finding. Worldwide prevalence is two hundredths, males on top of forty and set on the tongue, floor of the mouth, and buccal tissue layer (Fig-4). It means that a white patch. Associate internationally accepted definition states that a white plaque of uncertain risk having expelled different celebrated diseases that have non-malignant ${ }^{[27]}$. Smoking and alcohol users are at risk. Clinically seen as specked, nodular, and verrucous. Treatment is that the elimination of risk factors, biopsy, and observation for regression, later surgery. Different modalities are optical device, cryo, bleomycin, calcipotriol, and photodynamic medical care, etc.

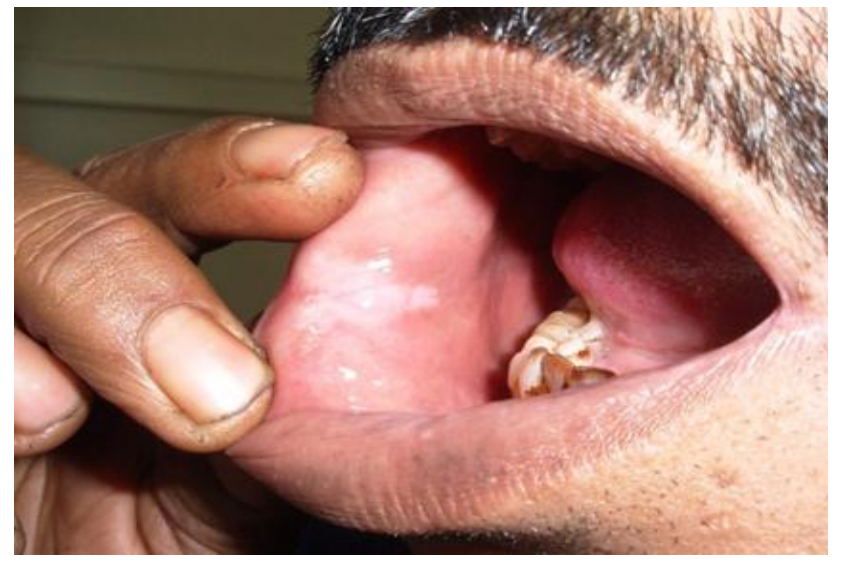

Fig. 4: Leukoplakia: White plaque at buccal mucosa.

j) Actinic cheilitis - it is an impending malignant form of the lip describe by accelerating tissue degeneration, a product of excessive exposure to ultraviolet sunlight ${ }^{[28]}$. Sites commonly implicated are the vermilion border of the lower lip in fair-skinned, occupied in outdoor occupation. It presented as solitary to multiple, keratotic, atrophic, scaly, erythematous, either well or poorly defined and resulting in the blurring of the vermilion border ${ }^{[29]}$.

k) Submucosal Fibrosis - it is chronic premalignant, suspected involving HLA A10. DR3, DR \& B7. Illustrate by fibroelastic changes and inflammation of the oral cavity ${ }^{[30]}$. Oropharynx and $1 / 3$ upper esophagus. A strong correlation has been noted with eating of spicy food, areca nuts, chilly, vitamin-B deficiency, and protein malnutrition. Early presentation is a burning sensation, exacerbated by spicy foods, blanching, and leathery mucosa and vesiculation. Late presentation is a fibrous band within mucosa which causes limitation of mouth opening, woody changes of mucosa /tongue and tightening of oropharyngeal opening. Treatment is done by submucosal steroids and collagenases injections, topical steroids, and iron orally. Severe case required surgery ${ }^{[31]}$.

Red Lesions of Oral Cavity - this type of lesions are produced by the vascular lesion.

Vascular Nevi - are cutaneous anomalies of vasculogenesis and angiogenesis; incidence is $6-25 \%$. Vascular nevi are classified as hemangiomas and lymphangiomas ${ }^{[32,33]}$. They are frequent over the lips. Most common benign tumor of childhood, often absent or small at birth and grow rapidly later on. There are slow involution and complete regression. Lymphangiomas usually grow as asymptomatic superficial or grouped vesicles in the buccal mucosa. At times result in macroglossia and interfere with feeding and speech $^{[34]}$. The treatment is hemiglossectomy. Causes are listed in Table 8.

Table 8: causes of vascular nevi

\begin{tabular}{|l|l|}
\hline $\begin{array}{l}\text { Syndrome with } \\
\text { oral hemangiomas }\end{array}$ & $\begin{array}{l}\text { Sturge-weber syndrome, Maffucci's } \\
\text { syndrome, Klippel-trenaunay syndrome, } \\
\text { Blue rubber bleb nevus syndrome }\end{array}$ \\
\hline
\end{tabular}

Mouth ulcers - are diverse and can be acute or chronic. No agreement concludes when an ulcer is called chronic but it is established that chronic ulcer is more than 2 weeks old. Occur in connection with many diseases, different mechanism, and no grave underlying basis. Causes are listed in Table 9. 
Table 9: Causes of ulcer

\begin{tabular}{|l|l|}
\hline Acute ulcer & $\begin{array}{l}\text { Aphthous ulcer, Traumatic ulcer, Behcet's } \\
\text { disease, Infections, Erythema multiforme, } \\
\text { Eosinophilic ulcer }\end{array}$ \\
\hline $\begin{array}{l}\text { Chronic } \\
\text { ulcer }\end{array}$ & $\begin{array}{l}\text { Drugs, Pemphigus, Lupus erythematosus, } \\
\text { Eosinophilic ulcer, Squamous cell carcinoma, } \\
\text { Reiter's disease. }\end{array}$ \\
\hline
\end{tabular}

a) Aphthous ulcer - additionally known as aphthous stomatitis or canker sores; it's a typical, disease poignant $10-25 \%$ of the population, etiology unclear. Increase the incidence of HLA. They're divided into three types ${ }^{[35]}$. Factors that incline are secretion, autoimmune, hypersensitivity, deficiency disease, tobacco, stress, etc. however less common in smokers ${ }^{[36]}$.

Minor ulcer - additionally known as Mikulicz, common, involves eightieth, presents as $2-4 \mathrm{~mm}, 1-5$ well outlined, spherical to an oval, superficial lesion, settled on cheeks, lips, the ground of mouth and tongue ventrum, with a pseudo-membrane.

Major ulcer - additionally known as Sutton's, involves ten, presents as quite 10mm, 1-6 in variety, painful, lasting perennial, common site are lips, soft palate.

Herpetiform - common in feminine adults, involves ten, presents as multiple vesiculations, $2 \mathrm{~mm}$, later painful ulceration, coalesce to create an oversize non-scar ulcer. Treatment is because associated, symptomatic if the cause is unknown. Smoothing or removing the traumatic cause, oral hygiene maintenance, antiseptic mouth wash, topical analgesic, topical steroid, topical antibacterial drug solution, oral vitamin B12, iron, and folate, steroid, teratogen, medication, Trental, levamisole, dapsone, etc.

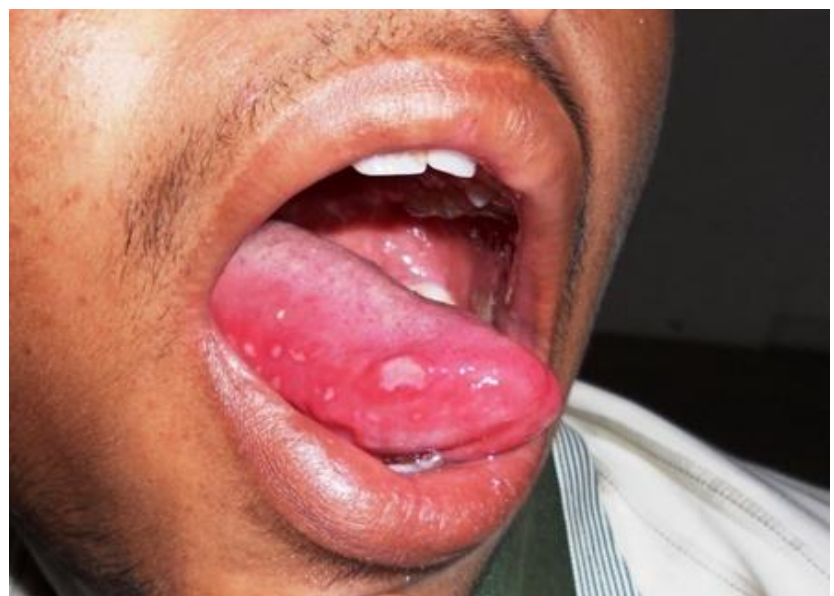

Fig. 5: Aphthous stomatitis: Round, a well-defined ulcer with a yellowish floor and erythematous halo.

b) Traumatic ulcer - these are caused by local trauma, cheek biting, fillings, crowns, rough brushing, chemical burns, braces, dentures, electric burns, and thermal burns. The mucosal layer is thinner than the skin and gets damaged easily ${ }^{[37]}$. Also, accidental biting can result in ulcers.

c) Behcet's syndrome - seen in 3-4 decades, etiologic factors are genetic, hematological, infectious, and immunological. It is systemic vasculitis with oral and genital ulcer, skin, ocular, cardiovascular, musculoskeletal, neurological, and gastrointestinal symptoms. Presents as a triad of aphthous ulceration, genetic ulcers and ocular lesions, ulcer heal with scarring. Treatment topical medication, oral colchicine other drugs like corticosteroids, levamisole, thalidomide, azathioprine, and cyclosporine, etc.

d) Eosinophilic ulcer - there are predominant eosinophils, so named as eosinophilic granuloma the common site is the tongue, it is asymptomatic, uncertain etiology, presents as a large ulcer, with an indurated border look like a malignant lesion.

e) Drug-induced Ulcer - many drugs have a side effect and can result in mouth ulcers ${ }^{[38,39]}$. Common examples are alendronate, methotrexate, nicorandil, propylthiouracil, and cocaine, etc.

f) Erythema Multiforme - it is a vesiculobullousmucocutaneous disease, trigger factors are a viral infection, drugs, and immune condition. Present as an erythematous area that forms multiple blister and rupture to form irregular, extensive, and painful erosion (Fig. 6).

Steven Johnson syndrome and toxic epidermal necrolysis-are typically drug-induced, more than $95 \%$ have oral ulcers, and initially, there is blister development that rips apart to form painful corrosion. On histology, there is necrosis of the entire epithelium and separated lamina propria.

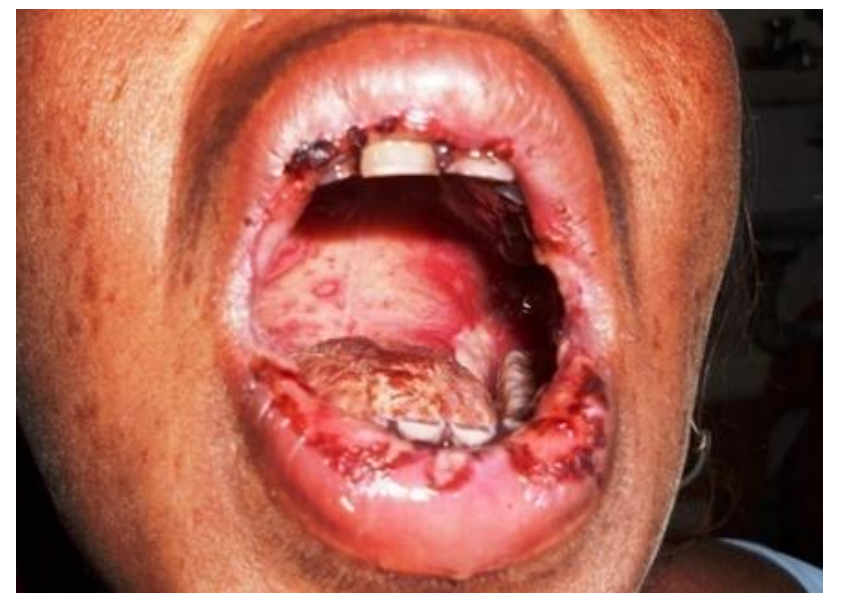

Fig. 6: Erythema multiforme: Multiple blisters break down to irregular, extensive erosion and extensive erythema.

g) Infective conditions - multiple infections that result in oral ulcers are listed in Table 10.

Table 10: Infective Causes of Mouth ulcer-

\begin{tabular}{|l|l|}
\hline Viral & $\begin{array}{l}\text { Chickenpox, Herpangina, HIV, Infectious } \\
\text { mononucleosis, Hand foot mouth disease }\end{array}$ \\
\hline Bacterial & $\begin{array}{l}\text { Acute necrotizing ulcerative gingivitis, Syphilis, } \\
\text { tuberculosis }\end{array}$ \\
\hline Fungal & Blastomycosis, Cryptococcosis, Histoplasmosis \\
\hline Parasitic & leishmaniasis \\
\hline
\end{tabular}

a) Viral infections - Herpes simplex- due to infection of herpes simplex virus-1. Primary infection is known as gingivostomatitis. Present as purple, boggy gingivitis; later develop vesicles that rupture to form painful ulcers with a yellow membrane (Fig. 7). The common sites are lips, tongue, oral mucosa, and palate. Heal spontaneously 7-14 days. Secondary infection presents as a vesicular lesion on the lip and vermilion border, very painful ulcer at gingiva and hard palate, heal with scab in 7-10 days. Treatment is to maintain oral hygiene, analgesics, increase fluid intake, and antivirals. 


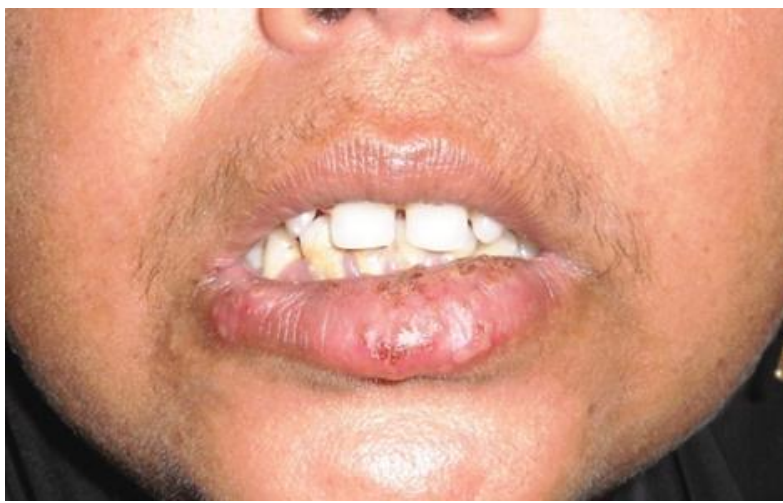

Fig. 7: Herpes Simplex: Multiple vesicles, cover with a yellowish membrane, distributed with swelling at the lower lip.

Varicella - present as an oral ulcer on the palate like herpetic stomatitis. Usually unilateral in the case of herpes zoster as involved nerve distribution is trigeminal (Fig. 8). When the geniculate ganglion of the facial nerve is involved it results in Ramsay hunt syndrome.

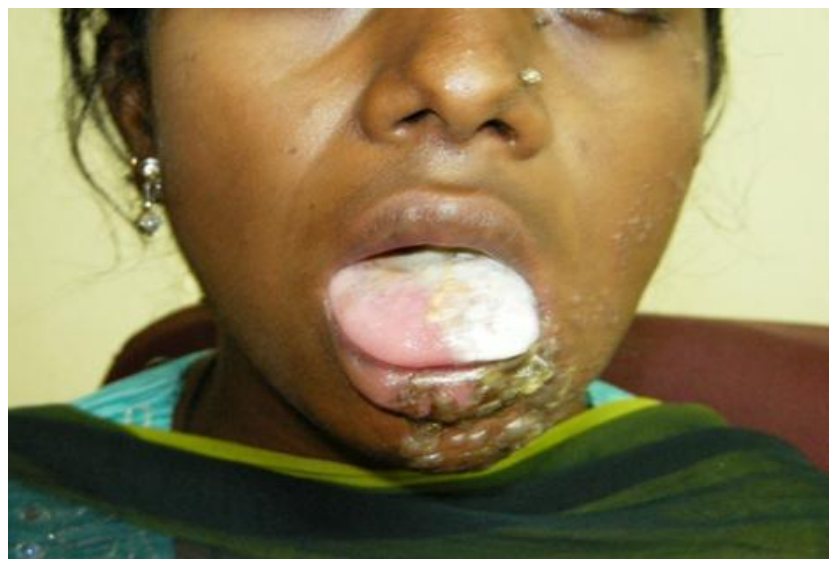

Fig. 8: Varicella: unilateral, multiple vesicles, crust, oral ulcers, distributed in the mandibular division of trigeminal nerve.

(Courtesy of Dr. P. Sagare, MRMC, Gulbarga).

HIV infection - infected HIV patients have oral lesions that can source bleeding and result in the discharge of the virus. Oral lesions in these individuals are due to malignant diseases, infection, and aphthous ulcers too.

Coxsackievirus - produces two clinical pictures, Herpangina- is a systemic disease of childhood, present with fever sore throat, and oropharynx vesicles. Hand foot mouth disease- common in children, present by vesicles in the oral cavity, palm, and soles fade away in a week.

\section{b) Bacterial infections}

Acute necrotizing ulcerative gingivitis, ANUG - also known as Vincent's angina, is frequent, polymicrobial, non-contagions, sudden onset, speedily progressive ${ }^{[40]}$, foul breath, the tip of interdental papilla ulceration, severe gum pain, with papillary necrosis. Predisposing factors are poor hygiene, malnutrition, stress, smoking, and immune defects. Causative organisms are fusiform bacteria, spirochetes, and borrelia vincentii ${ }^{[41]}$. Treatment is irrigation, increase oral hygiene, mouth wash, and debridement of necrotic tissue. Treatment failure can develop into cancrum-oris.

Syphilis - is an STD, the causative organism is treponema pallidum, oral lesions are there at any stage.
In the primary stage - at lips, tongue, hard palate Hunterian chancre is seen ${ }^{[42]}$. In the secondary stage$1 / 3^{\text {rd }}$ patient presents with painless snail track ulcers. In the tertiary stage- presents with gumma on the palate or tongue and breakdown in the painful, punched-out ulcer.

Tuberculosis - is an infection caused by Mycobacterium tuberculosis, in malnourished, generally affects the lungs but affects any part of the body ${ }^{[43]}$. Oral lesions are rare though sputum contains bacilli. Oral lesions classified as a primary- tuberculous chancre (rare, nodule breaks to form an ulcer), military tuberculosis. Secondarygranuloma, tuberculosis cutis orificialis(multiple, large, undermined ulcer) and tubercular osteomyelitis with mucosal connection ${ }^{\text {[44] }}$.

c) Fungal infections

Candidiasis - is that the most frequent oral zymosis, the five hundredth population has commensal as candida ${ }^{[45,46]}$. It's a pleomorphism plant life. it's a typical oral timeserving infection; predisposing factors embrace polygenic disease, HIV, medication, xerostomia. gift multiple dilemmas like Oral thrush, pseudomembrane fungal infection, acute/chronic symptom fungal infection, angular redness, and hyperplastic candidiasis [47]. Treatment is topical antifungals, clotrimazole, miconazole, nystatin, gentian violet, denture removal, hygiene maintenance, oral fluconazole, Itraconazole.

Histoplasmosis - rarely involve the oral cavity, only if progressive course. Present as numerous, superficial ulcers all over the oral cavity, even some form granuloma if become deeper.

Cryptococcosis - its presentation mimics candidiasis or blastomycosis. Mostly on the tongue when systemic spread takes place.

d) Leishmania infection - can involve lips, oral cavity, and rarely pharynx. It present as a papule that forms granulomatous ulcer and heals with fibrosis.

\section{Dermatologic conditions with oral involvement}

a) Oral Lichen Planus - is called when there is the involvement of oral mucosa. It is a T-cell mediated, cytotoxic, the chronic inflammatory reaction towards epithelial basal cell ${ }^{[48]}$. Present as painless but some feel soreness during eating/drinking. Six different forms are noted. Mentioned and described in Table 11. Diagnosis is made by patient history, examination, and histopathology. Treatment is improving oral hygiene, removal of precipitating causes, topical corticosteroid, calcineurin inhibitors, and oral steroids, acitretin, isotretinoin $^{[49]}$.

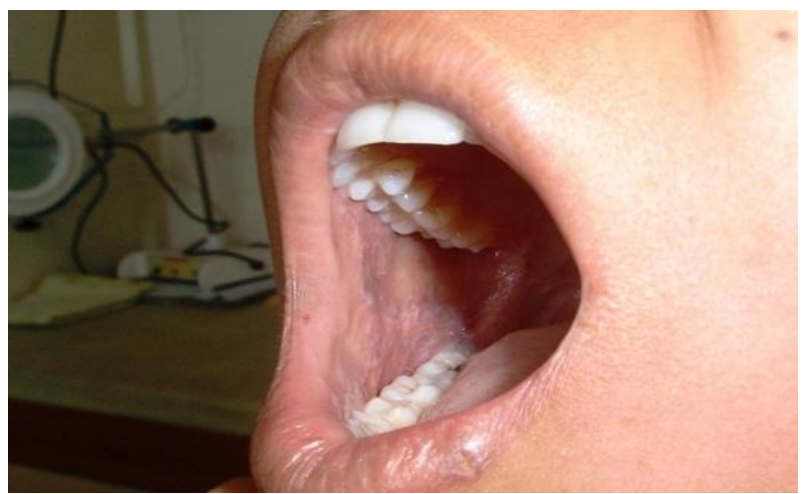

Fig. 9: Lichen Planus: Reticular type, net-like white lacy lines. 


\begin{tabular}{|l|l|}
\hline $\begin{array}{l}\text { Lesion } \\
\text { morphology }\end{array}$ & Details \\
\hline Reticular & $\begin{array}{l}\text { It is the most common asymptomatic form, } \\
\text { described by net-like white lacy lines, (Fig. 9) }\end{array}$ \\
\hline Ulcerative & $\begin{array}{l}\text { It is the second most common, described by } \\
\text { oral ulcerations and erosion with persistent, } \\
\text { irregular red areas, with yellow slough. }\end{array}$ \\
\hline Papular & $\begin{array}{l}\text { It is a transient phase, described by small, } \\
\text { white, asymptomatic, pinpoint papules, easily } \\
\text { missed in routine. }\end{array}$ \\
\hline Plaque & $\begin{array}{l}\text { It is described by large, homogenous white } \\
\text { patches that appear like leukoplakia. }\end{array}$ \\
\hline Atrophic & $\begin{array}{l}\text { It is described as an atrophic lesion with } \\
\text { erythema and radiating white striae at margins. }\end{array}$ \\
\hline Bullous & $\begin{array}{l}\text { It is a rare form, described by fluid-filled, } \\
\text { fluctuant vesicles, 2mm to 2cm, fluid is clear } \\
\text { but is hemorrhagic or purulent. Rupture } \\
\text { vesicles develop ulcerated surfaces. }\end{array}$ \\
\hline
\end{tabular}

a) Pemphigus - is an immune-mediated intraepithelial blistering disease with oral lesions ${ }^{[50]}$. There are antibodies against desmogleins located on desmosomes and develop an acantholytic intraepithelial blister, on direct immunofluorescence $\operatorname{IgG}$ or IgM in intercellular spaces ${ }^{[51]}$. Common sites are the soft palate, ventral tongue, and floor of the mouth that rip apart to develop painful ulcers with necrotic base. Treatment is maintaining oral hygiene, high dose oral steroids with immunosuppressants.

b) Paraneoplastic Pemphigus - usually it is a complication of malignancy. Recalcitrant painful oral erosion is the earliest and most steady finding. The disease often involves the lungs causing constrictive bronchiolitis. There is a minimum criterion by Anhalt- 1. Progressive, painful stomatitis with tongue involvement. 2 . Acantholysis or lichenoid dermatitis on histology. 3. Antiplakin antibodies demonstration. 4. Demonstration of neoplasm (mainly non-Hodgkin's lymphoma or Castleman's disease.).

c) Mucous Membrane Pemphigoid - this group of the immunological disease affects mucosa, occasionally skin and nasopharynx. Presents as vesicles, bullae, and ulcers. Histology shows subepithelial bullae, IgG, IgA, or complement $\mathrm{C} 3$ deposits throughout the basal membrane. Bullous pemphigoid is non scaring, blistering disorder, localized or generalized, $50 \%$ have oral lesions.

d) Reiter's syndrome - it is inflammatory arthritis, develops due to cross-reactivity means response to an infection of another part of the body ${ }^{[52]}$. Present as the triad of inflammatory symptoms viz. large joint arthritis, uveitis, and urethritis. In the oral cavity patient complaints of recurrent aphthous, migratory stomatitis, and geographic tongue ${ }^{[53]}$.

e) Linear IgA Disease - it is an autoimmune skin disease, a result of autoantigen, describe by circulating $\operatorname{IgA}{ }^{[54]}$. IgA autoantibodies cross-react with hemidesmosome of the basement membrane and detach the epidermis from the dermis and lead to blister formation ${ }^{[55]}$. Present as tense vesicles or bullae, in arciform, clear or hemorrhagic, surrounding a central crust described as a string of pearl. Common site face trunk and extremities, on face lesion, are perioral, oral ulcer and erosion, nasal stuffiness, and bleeding. f) Epidermolysis Acquisita - mucosal lesion is seen in 5$10 \%$ of patients. Illustrate by autoantibodies against collagen type VII. Described as skin fragility, tense blisters at non-inflamed skin over trauma prone sites like knee, elbow, ankles, toes, etc. often get mimicked with other blister diseases. The diagnostic test is the detection of serum autoantibodies against collagen VII ${ }^{[56]}$.

g) Dermatitis Herpetiformis - is an autoimmune blistering disease ${ }^{[57]} .75-90 \%$ associated with celiac disease. Seen in 15-40 yr of age, female predominance, present as itchy, papules, vesicles, erosions, and excoriation. Lesions located symmetrically on extensors, trunk, buttock etc ${ }^{[58]}$. Lesions are also seen in the oral mucosa. Associated with diabetes, thyroid, anemia, Vitiligo, etc.

h) Kawasaki Disease - is additionally referred to as tissue layer node syndrome ${ }^{[59]}$. It affects blood vessels throughout the body. Occurring in infants and youngsters. gift as high fever, red eyes, red tongue (strawberry), red lip, necrotizing microvasculitis, red palm, soles, venereal rash, inflammatory disease, and cervical lymphadenopathy.

i) Actinic keratosis - it is pre-malignant, seen in sunlight exposed worker ${ }^{[60]}$. Common site lower lip vermilion border. The lesion presents as, solitary to multiple, keratotic, atrophic, scaly, erosive, (Fig. 10) well or poorly demarcated at the vermilion border and result in blurring of the border. 6-10\% may develop squamous cell carcinoma ${ }^{[61]}$.

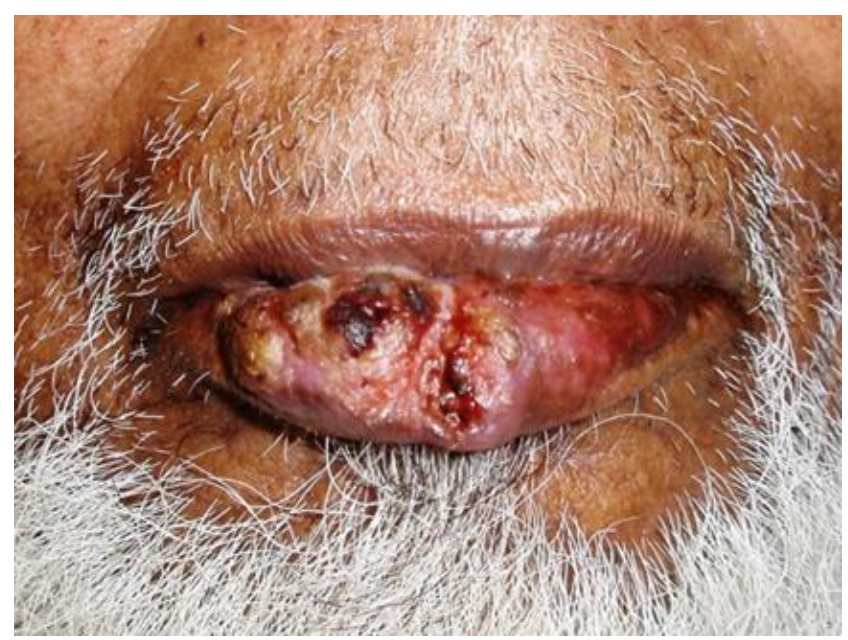

Fig. 10: Actinic keratosis: keratotic, atrophic, scaly, erosive, well-demarcated plaque at the lower lip.

\section{Conclusion}

The mouth is a straightforwardly available window of the body. In contemplation with development, composition, and utility oral cavity is only one of its kind. It is a two-way road as systemic skin disease has oral manifestation. Interpretation of the symptom and signs help in identification and early diagnosis of systemic diseases. Oral illness can bring into being from infection, inflammation or neoplastic, immunological, benign, or malignant. That's why the oral cavity should be examined in one piece from buccal mucosa, lips, tongue, gum, teeth, palate to the oropharynx. Knowledge of systemic diseases is vital in day to day clinical practice, often oral manifestation is the most significant or first sign of systemic illness. So dermatologists and dental surgeons are conscious of oral complaints and their association with systemic disease. 


\section{Consent of Publication}

Not applicable

\section{Conflict of Interest}

Nil.

\section{References}

[1] Rashmi sarkar and khushbu Goel, IADVL textbook of dermatology. Volume 2(4th ed). 2015; 54:2030-2071.

[2] Ireland, Robert (2010). A Dictionary of Dentistry. Oxford University Press. pp. 348-349.

[3] Bortoluzzi, MarceloCarlos; Capella, DiogoLenzi; Da Rosa, ThaianyNaila; Lasta, Renata; Presta, AndréiaAntoniuk; Traebert, Jefferson (2012). "Tooth loss, chewing ability and quality of life". Contemporary Clinical Dentistry. 3 (4): 393-7.

[4] Poulami Majumder, Vineet Nair, Malancha Mukherjee, Sujoy Ghosh, and Subrata Kumar Dey, "The Autosomal Recessive Inheritance of Hereditary Gingival Fibromatosis," Case Reports in Dentistry, vol. 2013, Article ID 432864, 4 pages, 2013.

[5] Thomas C. Hart, Yingze Zhang, Michael C. Gorry, P. Suzanne Hart, Margaret Cooper, Mary L. Marazita, Jared M. Marks, Jose R. Cortelli, Debora Pallos Am J Hum Genet. 2002 April; 70(4): 943-954. Published online 2002 February 2.

[6] Kahn, Michael A. Basic Oral and Maxillofacial Pathology. Volume 1. 2001.

[7] Montebugnoli L, Bernardi F. Cyclosporin an effect on extraoral connective tissue in heart transplanted patients. J Int Acad Periodontol. 1999;1:91-4.

[8] Morton RS, Dongari-Bagtzoglou AI. Regulation of gingival fibroblast interleukin-6 secretion by cyclosporine a. J Periodontol. 1999;70:1464-71.

[9] Deshmukh SN, Dive AM, Moharil R, Munde P. Enigmatic insight into collagen. J Oral Maxillofac Pathol. 2016;20:276-83.

[10] Bolzani G, Coletta RD, Junior HM, Almeida OP, Graner E. Cyclosporin a inhibits production and activity of matrix metalloproteinases by gingival fibroblasts. J Periodontal Res. 2000;35:51-8

[11] Johnson RB, Zebrowski EJ, Dai X. Synergistic enhancement of collagenous protein synthesis by human gingival fibroblasts exposed to nifedipine and interleukin-1-beta in vitro. $\mathrm{J}$ Oral Pathol Med. 2000;29:8-12.

[12] Shaddox, Luciana M; Walker, Clay B (2010-08-11). "Treating chronic periodontitis: current status, challenges, and future directions". Clinical, Cosmetic, and Investigational Dentistry. 2: 79-91

[13] Heitz-Mayfield LJ, Schätzle M, Löe H, et al. (October 2003). "Clinical course of chronic periodontitis. II. Incidence, characteristics, and time of occurrence of the initial periodontal lesion". J. Clin. Periodontol. 30 (10): 902-8.

[14] Van der Weijden GA, Timmerman MF (2002). "A systematic review on the clinical efficacy of subgingival debridement in the treatment of chronic periodontitis". J. Clin. Periodontol. 29 (S3): 55-71.
[15] Odell EW (Editor) (2010). Clinical problem-solving in dentistry (3rd ed.). Edinburgh: Churchill Livingstone. p. 192

[16] Meleti M, Vescovi P, Mooi WJ, van der Waal I. Pigmented lesions of the oral mucosa and perioral tissues: a flow-chart for the diagnosis and some recommendations for the management. Oral Surg Oral Med Oral Pathol Oral Radiol Endod. 2008;105:606-16.

[17] Eisen D. Disorders of pigmentation in the oral cavity. Clin Dermatol. 2000;18:579-87.

[18] Buchner A, Hansen LS. Pigmented nevi of the oral mucosa: a clinicopathologic study of 36 new cases and a review of 155 cases from the literature: Part I. A clinicopathologic study of 36 new cases. Oral Surg Oral Med Oral Pathol. 1987;63:566-72.

[19] Lakshminarayanan V, Ranganathan K. Oral melanoacanthoma: a case report and review of the literature. J Med Case Reports. 2009;3:11.

[20] Ho KK, Dervan P, O'Loughlin S, Powell FC. Labial melanotic macule: a clinical, histopathologic, and ultrastructural study. J Am Acad of Dermatol. 1993;28:33-9.

[21] Terrinoni A, Rugg EL, Lane EB, et al. (Mar 2001). "A novel mutation in the keratin 13 gene causing oral white sponge nevus". J. Dent. Res. 80 (3): 919-923.

[22] Smith, Frances JD; Hansen, C. David; Hull, Peter R.; Kaspar, Roger L.; McLean, WH Irwin; O’Toole, Edel; Sprecher, Eli (1993), Adam, Margaret P.; Ardinger, Holly H.; Pagon, Roberta A.; Wallace, Stephanie E. (eds.), "Pachyonychia Congenita", GeneReviews®, University of Washington, Seattle, PMID 20301457, retrieved 2018-08-01

[23] Eliason, Mark J.; Leachman, Sancy A.; Feng, Bing-jian; Schwartz, Mary E.; Hansen, C. David (October 2012). "A review of the clinical phenotype of 254 patients with genetically confirmed pachyonychia congenita". Journal of the American Academy of Dermatology. 67 (4): 680686.

[24] Sieff CA. Dyskeratosis Congenita. NORD Guide to Rare Disorders. Lippincott Williams \& Wilkins. Philadelphia, PA. 2003:104-5.

[25] Woo SB (2012). Oral Pathology: A Comprehensive Atlas and Text. Elsevier Health Sciences. p. 9.

[26] Cherry-Peppers, G; Daniels, CO; Meeks, V; Sanders, CF; Reznik, D (February 2003). "Oral manifestations in the era of HAART". Journal of the National Medical Association. 95 (2 Suppl 2): 21S-32S.

[27] Scully C (2008). Oral and maxillofacial medicine: the basis of diagnosis and treatment (2nd ed.). Edinburgh: Churchill Livingstone. pp. 216, 308, 310-312.

[28] Yanik EL, Katki HA, Silverberg MJ, et al; Leukoplakia, Oral Cavity Cancer Risk, and Cancer Survival in the U.S. Elderly. Cancer Prev Res (Phila). 2015 Sep8(9):857-63.

[29] Berman, B; Bienstock, L; Kuritzky, L; Mayeaux, EJ Jr; Tyring, SK (May 2006). "Actinic keratoses: sequelae and treatments. Recommendations from a consensus panel". The Journal of Family Practice. 55 (5): suppl 1-8.

[30] Treister NS; Bruch JM (2010). Clinical oral medicine and pathology. New York: Humana Press. p. 121.

[31] Aziz, SR (1997). "Oral submucous fibrosis: an unusual disease". Journal of the New Jersey Dental Association. 68 (2): 17-9. 
[32] Rao, N.R.; Villa, A.; More, C.B.; Jayasinghe, R.; Kerr, A.R.; Johnson, N.W. (2020). "Oral submucous fibrosis: a contemporary narrative review with a proposed interprofessional approach for early diagnosis and clinical management". journal of Otolaryngology-Head \& Neck Surgery. 49 (3): 1-11.

[33] Solomon LM, Esterly NB. Nevi and cutaneous tumors. In: Taeusch HW, Ballard RA, editors. Schaffer and Avery's diseases of the newborn. 6th ed. Philadelphia: WB Saunders Company; 1991. p. 997-1009.

[34] Requena L, Sangeguza OP. Cutaneous vascular proliferation: Part II. Hyperplasias and benign neoplasms. J Am Acad Dermatol 1997;37:887-920

[35] Chiller KG, Passaro D, Frieden IJ. Haemangiomas of infancy. Clinical characteristics, morphologic subtypes, and their relationship to race, ethnicity, and sex. Arch Dermatol 2002;138:1567-76.

[36] Scully, Crispian (2008). "Chapter 14: Soreness and ulcers". Oral and maxillofacial medicine: the basis of diagnosis and treatment (2nd ed.). Edinburgh: Churchill Livingstone. pp. 131-39.

[37] RA Cawson; EW Odell; S Porter (2002). Cawson's essentials of oral pathology and oral medicine (7. ed.). Edinburgh: Churchill Livingstone. pp. 178-91.

[38] Scully, Crispian (2008). "Chapter 14: Soreness and ulcers". Oral and maxillofacial medicine: the basis of diagnosis and treatment (2nd ed.). Edinburgh: Churchill Livingstone. pp. 131

[39] Kharazmi M, Sjöqvist K, Warfvinge G (April 2012). "Oral ulcers, a little known adverse effect of alendronate: a review of the literature". Journal of Oral and Maxillofacial Surgery. 70 (4): 830-36.

[40] Healy CM, Smyth Y, Flint SR (July 2004). "Persistent nicorandil induced oral ulceration". Heart. 90 (7): e38.

[41] Karring, edited by Jan Lindhe, Niklaus P. Lang, Thorkild (2008). Clinical periodontology and implant dentistry (5th ed.). Oxford: Blackwell Munksgaard. pp. 413, 459.

[42] Scully, Crispian (2008). Oral and maxillofacial medicine: the basis of diagnosis and treatment (2nd ed.). Edinburgh: Churchill Livingstone. pp. 101, 347.

[43] Syphilis". CDC. 4 June 2015. Archived from the original on 21 February 2016. Retrieved 3 February 2016.

[44] "Tuberculosis (TB)". World Health Organization (WHO). 16 February 2018. Retrieved 15 September 2018.

[45] Behera, D. (2010). Textbook of Pulmonary Medicine (2nd ed.). New Delhi: Jaypee Brothers Medical Publishers. p. 457.

[46] Bouquot BW, Neville DD, Damm CM, Allen JE (2002). Oral \& maxillofacial pathology (2. ed.). Philadelphia: W.B. Saunders. pp. 189-197. ISBN 978-0-7216-9003-2.
[47] Lalla RV, Patton LL, Dongari-Bagtzoglou A (April 2013). "Oral candidiasis: pathogenesis, clinical presentation, diagnosis and treatment strategies". Journal of the California Dental Association. 41 (4): 263-8.

[48] "Symptoms of Oral Candidiasis". cdc.gov. February 13, 2014. Archived from the original on 29 December 2014. Retrieved 28 December 2014.

[49] Roopashree MR, Gondhalekar RV, Shashikanth MC, George J, Thippeswamy SH, Shukla A (November 2010). "Pathogenesis of oral lichen planus--a review". Journal of Oral Pathology \& Medicine. 39 (10): 729-34.

[50] Thongprasom K, Carrozzo M, Furness S, Lodi G (July 2011). "Interventions for treating oral lichen planus". The Cochrane Database of Systematic Reviews (7): CD001168.

[51] Yeh SW, Ahmed B, Sami N, Ahmed AR (2003). "Blistering disorders: diagnosis and treatment". Dermatologic Therapy. 16 (3): 214-23.

[52] Beutner, EH; Jordon, RE (November 1964). "Demonstration of skin antibodies in sera of pemphigus vulgaris patients by indirect immunofluorescent staining". Proc. Soc. Exp. Biol. Med. 117 (2): 505-510.

[53] American College of Rheumatology. "Reactive Arthritis". Retrieved January 24, 2017.

[54] Zadik Y, Drucker S, Pallmon S (Aug 2011). "Migratory stomatitis (ectopic geographic tongue) on the floor of the mouth". J Am Acad Dermatol. 65 (2): 459-60.

[55] Freedberg, et al. (2003). Fitzpatrick's Dermatology in General Medicine. (6th ed.). McGraw-Hill.

[56] Antiga E, Caproni M, Fabbri P. Linear immunoglobulin a bullous dermatosis: the need for an agreement on diagnostic criteria. Dermatology. 2013;226(4):329-32.

[57] Hammers CM, Stanley JR. Mechanisms of disease: pemphigus and bullous pemphigoid. Annu Rev Pathol. 2016;11:175-197.

[58] Freedberg, et al. (2003). Fitzpatrick's Dermatology in General Medicine. (6th ed.). McGraw-Hill.

[59] Bolotin, Diana; Petronic-Rosic, Vesna (2011). "Dermatitis herpetiformis". Journal of the American Academy of Dermatology. 64 (6): 1017-1024.

[60] Rapini, Ronald P.; Bolognia, Jean L.; Jorizzo, Joseph L. (2007). Dermatology: 2-Volume Set. St. Louis: Mosby. pp. $1232-4$.

[61] Bickers DR. Photosensitivity and other reactants to light. In: Kasper DL, et al., editors. Harrison's Principles of Internal Medicine. 16th ed. New York: McGraw-Hill; 2005. pp. 324-329.

[62] Ackerman AB, Mones JM. Solar (actinic) keratosis in squamous cell carcinoma. Br J Dermatol. 2006;155:9-22. 